\title{
ENSAYO
}

\section{La cultura marxista en la Argentina de los últimos cuarenta años}

\author{
Ariel Petruccelli \\ Universidad Nacional del Comahue \\ arpetrus@gmail.com
}

Titulo: Marxist culture in Argentina of the last 40 years

Resumen: En este trabajo se realiza una cartografia de la producción intelectual marxista (tanto la producida dentro y fuera de las organizaciones políticas, como dentro y fuera del mundo académico) en la Argentina, en el período comprendido entre el retorno de la democracia, en 1983, y 2020.

Palabras clave: marxismo - cultura - campo intelectual - academia

\begin{abstract}
In this work, a cartography of Marxist intellectual production in Argentina is carried out (both that produced inside and outside of political organizations, as well as inside and outside the academic world), in the period between the return of democracy, in 1983, and 2020.
\end{abstract}

Keywords: marxism - culture -intellectual field - academia

Recepción: 1 de diciembre de 2020. Aceptación: 25 de febrero de 2021

$$
* * *
$$

Quien observara el panorama intelectual argentino en la bisagra de los años 80 y 90, bien podría dudar que el marxismo continuara siendo una corriente intelectual relevante dos o tres décadas después. La con- 
fluencia del fracaso de los intentos revolucionarios latinoamericanos en los años 70, las masacres de terrorismo de estado, la crisis y posterior derrumbe del mundo soviético y el ascenso mundial del neoliberalismo se conjugaban configurando un negro presente y un muy incierto futuro. Las figuras que habian alimentado una pequeña pero vital cultura intelectual marxista en las décadas anteriores habian mayormente desaparecido, y las fuerzas de relevo (formadas fundamentalmente en los poco propicios "años de plomo") todavía casi no se dejaban ver. En cierta medida, esto se correspondía con tendencias mundiales: el auge del posmodernismo y el concomitante retroceso del marxismo, en un mundo crecientemente neoliberalizado y con casi todos los proyectos socialistas que habian alcanzado el poder estatal, en el pasado, en proceso de derrumbe o reorientación procapitalista. Sin embargo, aunque esta era la tendencia general, el panorama poseía notorias diferencias locales. Por ejemplo, mientras que el marxismo intelectual francés prácticamente había desaparecido en la década de los 70 , en el mundo angloparlante el marxismo vivió desde entonces una nueva vitalidad, en disputa o colaboración con otras "teorías críticas".

Pletóricos de acción y militancia con anhelos revolucionarios, los años 60 y 70 habían dado lugar a una producción intelectual marxista no desdeñable en Argentina (aunque quizá no tan abundante en comparación con la acción y la organización). Pero los fragores de esos años, la represión estatal y paraestatal o el mero paso del tiempo hicieron lo suyo. Milcíades Peña se había suicidado (a los 32 años) en 1965; Carlos Astrada había muerto en 1970; Silvio Frondizi fue asesinado por la Triple A en 1974; José Luis Romero falleció en Tokio en 1977; Rodolfo Puiggrós murió en 1980 (exiliado en Cuba); Héctor Agosti en 1984, al igual que Horacio Ciafardini (a la temprana edad de 41 años); Luis Franco en 1988, José Aricó en 1991. No hay manera de saber cuántos de los asesinados y desaparecidos antes y durante la dictadura hubieran devenido intelectuales marxistas, pero pocas dudas puede haber de que la sangría de esos años proporcionó un golpe tremendo a la cultura marxista.

El retorno a la democracia en 1983 halló poquísimos intelectuales marxistas vivos, casi todos en el exilio. A su regreso, buena parte habian abandonado sus sueños revolucionarios, y aunque en algunos casos (como el de José Aricó) su interés por el marxismo no desapareció, podia dudarse que sus preocupaciones marxistas tuvieran continuadores entre quienes, siendo más jóvenes, los rodeaban: el marxismo era un equipaje demasiado pesado para quienes quisieran hacer meramente un viaje académico, y una teoría demasiado sofisticada para simplemente defender la democracia liberal. Para quien hubiera borrado del horizonte de las humanas posibilidades el socialismo y la revolución, el marxismo 
podía ser un interesante objeto de tesis, pero dificilmente lo considerara una corriente intelectual vital a la que valiera la pena desarrollar.

José Aricó, Oscar del Barco, José Sazbón, Emilio de Ípola o Juan Carlos Portantiero (entre otros) eran en los 80 intelectuales activos y originales, agudos conocedores de la tradición marxista y no completamente alejados de sus problemáticas. Pero a diferencia de años anteriores, ya se hallaban fuera de toda vinculación, así sea indirecta, con alguna fuerza revolucionaria, e incluso alejados de cualquier acción política que no fuera intelectual. Ernesto Laclau y Enrique Dussel -buenos conocedores de la tradición marxista y con innegables preocupaciones políticas-ya no regresarian más que de manera ocasional. La trayectoria intelectual en Argentina de Adolfo Gilly fue escasa. Miguel Benasayag, de interesantes intervenciones en los últimos lustros, continúa viviendo en Europa.

En los años 70 lo que hubo fue un marxismo del exilio: el exterior y el interior. Un marxismo de catacumbas, de grupos de estudio cuasi clandestinos. En los años 80 algo había cambiado: se podía dar la cara, hablar a cielo abierto. Pero la luz que arrojaba el descubrimiento del velo de la dictadura mostraba una cruda realidad: la producción intelectual marxista era casi insignificante. Los viejos intelectuales marxistas habian desaparecido en su mayor parte. Los pocos que sobrevivian se hallaban insertos en un proceso de creciente academización, abandono de perspectivas revolucionarias y reducción a un mínimo de sus vinculaciones políticas. Su interés en el marxismo tendía a menguar, si no a desaparecer. Había alguna producción para entender la crisis del marxismo y de las frustradas o derrotadas revoluciones latinoamericanas, pero ya escasa expectativa y mucho menos voluntad de relanzar los viejos proyectos políticos e intelectuales. Aunque todavia con grandes riquezas teóricas y envidiable capacidad reflexiva (sobre todo en las fragmentarias obras de Aricó y de Sazbón); se trataba de una suerte de marxismo residual, que abría serios interrogantes sobre su continuidad.

A años luz de este pequeño universo intelectual, las organizaciones políticas marxistas que habian sobrevivido a la dictadura continuaban tozudamente su acción y su organización en los márgenes de la vida politica. Eran en general pequeños grupos muy activos, pero con escaso desarrollo intelectual. Aunque cada pequeño grupo militante mantuvo su prensa, sus vínculos internacionales y una abundante producción escrita, se trataba casi sin excepciones de una producción intrínsecamente autocentrada y autorreferencial, que podía ignorar no solamente la producción intelectual ajena al marxismo, sino inclusive la producción de otras tradiciones marxistas. Un militante del "sector intelectual" de un partido trotskista-para poner un tipo de ejemplo que este autor experimentó personalmente- podía manejar un arsenal de citas de Lenin y Trotsky, Moreno o Altamira, pero no saber casi nada 
de Gramsci o Athusser e incluso ignorar la existencia de Hobsbawm o Anderson. No hablemos ya de la producción intelectual no marxista. Entre tanto, el estallido del MAS a comienzos de los 90 fragmentó a las izquierdas militantes en mil pedazos. Si el futuro del marxismo como tradición intelectual se presentaba incierto, lo mismo sucedía con el marxismo como fuerza politica.

$$
* * *
$$

No hay ninguna manera de delimitar de forma precisa dónde comienza y dónde termina el marxismo y, por consiguiente, quiénes pueden ser considerados marxistas y quiénes no (o cuán marxista puede ser considerada una obra, una práctica, un autor o una autora). Y esto es así no por carencias intelectivas, sino por su naturaleza esencial. Para decirlo con las palabras de Manuel Sacristán en una anotación de lectura de una obra de Agnes Heller: "En general, el hecho del evidente pluralismo marxista no admite más que dos interpretaciones: o el marxismo se reduce a las pocas teorias comunes, o es una cultura, no una teoría, una consciencia colectiva, etc. Mi tesis". En consonancia con Sacristán, pues, aquí consideraré al marxismo como una cultura.

Ahora bien, si concebimos al marxismo como una cultura y aceptamos su pluralidad, ello no significa que cualquier cosa pueda ser considerada marxista o marxismo. No hay fronteras nítidas, desde luego, pero hay algunos rasgos mínimos comunes. La siguiente definición de Jon Elster me parece justa:

El marxismo se define principalmente por [...] dos rasgos. Primero, la creencia en que la alienación y la explotación impiden a los seres humanos vivir bien y que su supresión es no sólo deseable sino factible. O como mínimo, que no se ha demostrado que no sea factible suprimirlas. Segundo, el marxismo se caracteriza por unos pocos supuestos teóricos fundamentales sobre la estructura y el desarrollo de las sociedades que hacen hincapié en la interrelación entre los derechos de propiedad, el cambio técnico y la lucha de clases. De éstos, el primer elemento, de carácter normativo, constituye el sine qua non del marxismo. El segundo elemento, de carácter explicativo, puede ser modificado y revisado hasta cierto punto sin pérdida de identidad. Sólo hasta cierto punto, sin embargo, puesto que la propia teoría normativa tendría que ser abandonada si se demostrara que las propuestas marxistas son radicalmente imposibles [...]. (Elster, 1987: 52)

Para los efectos del presente trabajo no necesitamos ninguna defi- 
nición más precisa. Aquí analizaremos la producción intelectual marxista, vale decir, ante todo la obra escrita en claves filosóficas, teóricas histórico-sociológicas e interpretativas dentro del universo marxista, definido de esta manera laxa pero no carente de contornos. La producción intelectual marxista se desarrolla tanto dentro como fuera de organizaciones politicas, dentro y fuera del mundo académico. No será objeto específico del presente trabajo ni las formas de construcción de organizaciones politicas, ni las acciones o intervenciones sindicales, ni los posicionamientos tácticos o coyunturales, aunque tampoco se puede ignorar completamente ninguna de estas dimensiones.

Comencemos por el panorama que se podía observar luego del retorno a la democracia en 1983. En líneas generales, podriamos decir que durante la segunda mitad de los años 80 y durante la década de los 90 la producción intelectual marxista se afincó primordialmente en una pléyade de revistas independientes, tanto de los partidos políticos como de la academia. Desde luego, en los límites, algunas publicaciones comenzaban a adecuarse crecientemente a las normas de la producción científico-académica hoy en boga, pero por entonces no del todo establecidas, sobre todo en América Latina: especialización disciplinar o subdisciplinar; "indexación" en sistemas científicos internacionales; referato con sistema "doble ciego"; reducción a un mínimo de las dimensiones ideológicas o políticas; tendencial uniformización del lenguaje, el estilo y las normas de edición; exigencia de erudición con referencia a un cierto canon establecido. En el polo opuesto, algunas de estas publicaciones podían considerarse a sí mismas casi como un embrión de partido político o tener tendencias latentes hacia la constitución de una organización política en términos más tradicionales. Pero, en general, lo preponderante fue un tipo de revista con motivaciones mucho más político-intelectuales que estrechamente académicas, pero sin pertenencia a ninguna organización política preexistente. Sus textos tenían intereses y perspectivas amplios y totalizantes (antes que particulares o especializados). Aunque su tirada solía ser escasa, se dirigian a un público intelectual potencialmente amplio y diverso, no a un reducido nicho de especialistas en algún tema.

Entre las publicaciones más destacadas podemos mencionar a Praxis (1983-1986), Cuadernos del Sur (1985-2005), Doxa (1990-2000), Debate Marxista (1991-1999), El Cielo por Asalto (1991-1994), Acontecimiento (1991-2016), Dialéktica (1992 y continúa), El Rodaballo (1994-2006), Razón y Revolución (1995-2017), Taller (1996-2006), Herramienta (1996 y continúa). 
En mayor o menor medida, con diferentes orientaciones y con mejor o peor fortuna en el cumplimiento de sus objetivos, en estas publicaciones podemos hallar intentos de introducir nuevos temas y nuevos autores o autoras, en ocasiones por medio de traducciones de lenguas extranjeras; intentos por repensar los problemas del socialismo; ajustes de cuenta con las experiencias pasadas; innovaciones teóricas; y muy desigualmente: voluntad crítica y dialógica.

Las organizaciones más clásicamente políticas, desde luego, continuaban (y continúan) produciendo publicaciones teóricas: por ejemplo Estrategia Internacional o Lucha de Clases (PTS), En Defensa del Marxismo (PO), Debate Marxista (MAS), Socialismo o Barbarie (Nuevo MAS), Politica y Teoría (PCR). Pero en los años 80 y 90 lo hacían con escasa voluntad y capacidad de innovación: el suyo era predominantemente un marxismo a la defensiva, más preocupado por apuntalar las viejas verdades que por analizar nuevos problemas. Su tónica era fuertemente autocentrada: más preocupada por establecer demarcaciones que diálogos; por evitar la contaminación por parte de otras tradiciones, antes que por aprender algo de ellas; con demasiada premura por refutar textos o perspectivas que rara vez eran estudiadas con detenimiento, y nunca en sus propios términos (antes de criticarlas desde premisas diferentes a las suyas). Lejos de ser una genuina preocupación en sí misma, para las publicaciones partidarias la producción intelectual tenía un carácter muchas veces instrumental: justificar la línea politica de la organización. Y el universo de sus referencias se hallaba centrado (sintoma inequívoco de una actitud defensiva) en autores clásicos, con escaso conocimiento de las producciones recientes. Hubo algunas excepciones, por supuesto, pero la tendencia general es la apuntada.

En el mundo académico había escasos enclaves marxistas. Algunas figuras individuales se identificaban como marxistas o empleaban ampliamente literatura marxista en sus clases (por ejemplo José Sazbón, Horacio Tarcus, Carlos Astarita, Emilio de Ípola, Oscar Terán). Más extraño todavía eran los colectivos o centros de investigación adscritos a perspectivas marxistas de investigación: la más notoria excepción es la del Centro de Investigaciones en Ciencias Sociales (CICSO), creado en 1966 y aún activo, dirigido por entonces por Beba Balvé.

La publicación y difusión de libros del marxismo internacional por parte, sobre todo, de los grandes sellos (Fondo de Cultura Económica y Siglo XXI) se retomó luego de 1983; pero su impacto era dispar. La editorial El Cielo por Asalto fue en los 80 y 90 un pequeño oasis local de publicaciones y traducciones de calidad, marxistas y de izquierda en general.

Prescindiendo del escaso volumen de lectores de todas las publicaciones en mayor o menor medida identificadas con el marxismo, su 
producción no parece insignificante en lo que hace a textos relativamente breves. A largo plazo, sin embargo, la pujanza de una corriente intelectual debe manifestarse tarde o temprano en obras mayores (aunque no sea este un índice completamente seguro). Aquí el panorama era mucho más desolador. Luego de la gran sequía del período de la dictadura de 1976-1983, no hubo ningún florecimiento: la producción de libros de inspiración o temática marxistas fue relativamente escasa durante la segunda mitad de los años 80 y la primera mitad de los 90 . Solitarios sobrevivientes de pasadas generaciones, León Rotzitchner (1924-2011), Alberto J. Pla (1926-2008), José Aricó (1931-1991) y Emilio de Ípola (1939) continuaban su producción. Rotzitchner dio a conocer Perón: entre la sangre y el tiempo en 1985, en tanto que Pla publicó en el período que analizamos: Introducción a la historia general del movimiento obrero (1984), Historia y socialismo (1988), La Internacional comunista y América Latina (1996), América Latina, mundialización y crisis (2001). Ninguna de estas obras trataba específicamente del marxismo, aunque estaban escritas desde perspectivas que podriamos considerar marxistas. Emilio de Ípola publicó Ideología y discurso populista en 1983. José Aricó -quien en 1982 había publicado en México su fundamental Marx y América Latina- publicaría La cola del diablo en 1988; luego, póstumamente, se daría a conocer La hipótesis de Justo (1999). Pero estas cuatro figuras eran (junto a Inés Izaguirre, Beba Balvé y Guillermo Almeyra) sobrevivientes excepcionales entre quienes se habian formado antes de la dictadura de 1976-1983.

Por alguna razón sobre la cual cabría indagar, quienes integran la siguiente generación -aquella que inició su formación en torno a los años 70- a pesar de una gran actividad intelectual juvenil sumamente rica en traducciones, edición de revistas, ensayos y polémicas, en general no produjeron obras extensas hasta pasados los cuarenta años de edad. Una excepción parcial podría ser Pablo Pozzi, quien publicó Oposición obrera a la dictadura en 1988, y Argentina entre el orden y el desorden internacional, en 1989 (a sus 35-36 años de edad). Lo mismo podría decirse de Pablo Rieznik (1949-2015), quien dio a conocer Endeudamiento externo y crisis mundial: antecedentes sobre el caso brasileño, en 1986. Pero los primeros libros publicados por Atilio Boron (1943) lo fueron en 1991: se trata de Estado, capitalismo y democracia en América Latina (en realidad una compilación de artículos) y Memorias del capitalismo salvaje. Juan Iñigo Carrera editó El conocimiento dialéctico en 1992, en tanto que su hermano, Nicolás Iñigo Carrera, publicó Estrategias de la clase obrera argentina: la huelga general politica de agosto de 1933 en 2006. Eduardo Grüner (1946) publicó sus primeros libros en 1993: Del positivismo a la emergencia del nacionalismo reaccionario (1880-1910) y La palabra dominante: la constitución del discurso autoritario en la 
cultura politica de la Argentina moderna (1880-1945). Carlos Astarita (1951) dio a conocer Desarrollo desigual en los origenes del capitalismo en 1992; su hermano, Rolando Astarita, publicó Valor, mercado mundial y globalización recién en 2004. Claudio Katz (1954) editó Economía latinoamericana: de la década perdida a la nueva crisis en 1993. Horacio Tarcus (1955) lanzó El marxismo olvidado en Argentina: Silvio Frondizi y Milcíades Peña en 1996. Todos estos autores publicarán en los años sucesivos una gran cantidad de libros en los que el marxismo es objeto y/o inspiración. En sus inicios, con todo, sus reflexiones fueron intentos aislados, inequívocamente marginales, producciones a contracorriente. Desde ángulos diferentes y diversa calidad, mantuvieron el interés intelectual por el marxismo en tiempos en que la tendencia general era su abandono.

Entre 1976 y 1996 los libros publicados por autores declaradamente marxistas o que tuvieran en el marxismo una fuente fundamental de inspiración fueron pocos. Aunque el listado que hemos brindado no es exhaustivo (sobre todo en lo que hace a textos no explícita o autodeclaradamente marxistas, pero sí muy influidos por esta tradición), pocas dudas pueden quedar de que se trataba de una producción cuantitativamente escasa, cosa que se hace muy nítida si la comparamos con los 23 años transcurridos desde entonces al presente.

$$
* * *
$$

Hacia la segunda mitad de los años 90 la producción de libros de inspiración marxista experimenta una aceleración. Coincidiendo con su etapa de madurez, la generación formada en torno a los años 70 o primeros 80 continúa la publicación de textos: entre los más destacados, Atilio Boron da a conocer Tras el búho de Minerva en el año 2000. Horacio Tarcus publica Mariátegui en la Argentina, o las politicas culturales de Samuel Glusberg (2001). La producción de esta generación se solapa, en la segunda mitad de los años 90 y primeros 2000 con un puñado de obras escritas por integrantes de la siguiente generación que iniciaban su trayectoria con cierta precocidad en la producción de libros. En 1998, Néstor Kohan (1967) publica Marx en su tercer mundo y, en 2000, De Ingenieros al Che: ensayos sobre el marxismo argentino y latinoamericano. En 1998, Ariel Petruccelli (1971) da a conocer Ensayo sobre la teoría marxista de la historia. En el mismo año Ezequiel Adamovsky (1971) edita el libro de entrevistas Octubre hoy: conversaciones sobre la idea comunista a 150 años del Manifiesto y 80 de la revolución rusa. Omar Acha (1971) publica en 2000 El sexo de la historia. Miguel Mazzeo (1966) ya había publicado el breve Volver a Mariátegui en 1995. Estos autores acrecientan rápidamente sus publicaciones a partir de aquí, y poco a 
poco se van sumando obras de quienes podrian considerarse parte de la misma generación en términos estrictamente cronológicos.

Con el inicio del siglo XXI la producción de obras de inspiración marxista o con el marxismo como objeto central, pues, se acelera notoriamente. La generación formada entre la segunda mitad de los 70 y la primera de los 80 continúa plenamente productiva: Horacio Tarcus publica en 2007 dos obras monumentales: Diccionario biográfico de la izquierda Argentina y Marx en Argentina, seguidos por El socialismo romántico en el Río de la Plata (2016). Rolando Astarita publica nada menos que siete libros de economía marxista entre 2006 y 2011, entre ellos Monopolio, imperialismo e intercambio desigual y El capitalismo roto; en tanto que su blog personal recibe a diario miles de visitas y es un muy activo núcleo de discusiones teóricas y políticas. Juan Iñigo Carrera publica varios libros, referidos sobre todo a la renta de la tierra, la formación económica argentina y El capital de Marx (entre ellos La renta de la tierra y El capital: razón histórica, sujeto revolucionario y conciencia). Pablo Pozzi edita varias obras sobre historia de los trabajadores (algunas de ellas en coautoría con Alejandro Schneider) y de las izquierdas, entre las que podemos destacar Historias del PRT I y II (2005 y 2008 respectivamente). Atilio Boron continúa plenamente activo, al igual que Carlos Astarita en su especialización medieval, Claudio Katz en economía, Eduardo Grüner en sociología y Nicolás Iñigo Carrera en historia. Elias Palti -quien hasta entonces no había tenido al marxismo como marco de referencia de su abundante producción intelectual-da a conocer el influyente y polémico Verdades y saberes del marxismo (2005). Por su parte, la generación de quienes se formaron sobre todo en los 90, superada las primeras instancias relativamente precoces, se halla quizá en su apogeo productivo. Gisela Catanzaro y Ezequiel Ipar dan a conocer Las aventuras del marxismo en 2003. Guillermo David da a luz Carlos Astrada: la filosofía argentina en 2004. Ignacio Lewkowicz publica Pensar sin estado también en 2004, en debate con la tradición marxista. Alejandro Schneider publica varios trabajos, entre los que destaca Los compañeros: trabajadores, izquierda y peronismo (1955-1973), publicado en 2005. Eduardo Sartelli (1963) edita varias obras, como La plaza es nuestra (2005), La cajita infeliz (2005) o la compilación Patrones en la ruta (2008). Omar Acha da a conocer una gran cantidad de obras de historia y ensayos de diferente tenor, escritos siempre desde perspectivas genéricamente marxistas. Aquí cabe mencionar especialmente los dos libros en los que historió a dos intelectuales marxistas: La trama profunda: historia y vida en José Luis Romero (2005) y La nación futura: Rodolfo Puiggrós en las encrucijadas argentinas del siglo XX (2006); su pequeño pero influyente La nueva generación intelectual: incitaciones $y$ ensayos (2008) y Un revisionismo histórico de izquierda (2012). Néstor 
Kohan publica una enorme cantidad de libros, algunos de ellos de divulgación -como Marxismo para principiantes; Gramsci para principiante; Fidel para principiantes-; otros de mayor enjundia, entre ellos Fetichismo e ideología en tiempos de rebelión (2005) y Ciencias sociales y marxismo latinoamericano (2014). Laura Sotelo (1965) publica Ideas sobre la historia: la Escuela de Frankfurt: Adorno, Horkheimer y Marcuse, en 2009. Hernán Camarero (1966) publica A la conquista de la clase obrera: los comunistas y el mundo del trabajo en la Argentina, 1920-1935, en 2007. Ariel Petruccelli publica la trilogia formada por Materialismo histórico: interpretaciones y controversias (2010), El marxismo en la encrucijada (2010) y Ciencia y utopía en Marx y la tradición marxista (2015). Además de varias obras menores -como Qué no hacer o Conjurar a Babel- Miguel Mazzeo publica en 2013 su extensa obra dedicada a Mariátegui: El socialismo enraizado. Fernando Lizárraga (1966) publica El marxismo y la justicia social en 2011, seguido de Marxistas y liberales (2015). Juan Dal Maso (1977) presenta El marxismo de Gramsci (2016), seguido de Hegemonía y lucha de clases (2018) y (en coautoria con Ariel Petruccelli) Althusser y Sacristán: itinerarios de dos comunistas críticos, en 2020.

En la segunda década del siglo XXI, además, comienzan a sumarse los primeros libros de la generación de quienes iniciaron su trayectoria luego de 2001. Facundo Nahuel Martín publica Marx de vuelta (2014) y Teoria critica de la modernidad (2020); Juan Kornblihtt Crítica del marxismo liberal: competencia y monopolio en el capitalismo argentino (2008); Martín Cortés, Un nuevo marxismo para América Latina (2015); Julia Expósito, El marxismo inquieto (2018); Santiago Roggerone, ¿Alguien dijo crisis del marxismo? (2018); Emiliano Exposto y Gabriel Rodríguez Varela dan a conocer El goce del capital: crítica del valor y psicoanálisis (2020).

A todo esto habria que agregar una gran cantidad de trabajos en los que -sin tener siempre al marxismo como objeto de estudio, o sin que sus autores o autoras se consideren especifica o principalmente marxistas- es posible observar indudables influencias de esta tradición. Maristella Svampa, Roberto Gargarella, Pablo Stefanoni y Ezequiel Adamovsky podrian ser acaso las figuras más relevantes de esta zona fronteriza (como a caso Guillermo O’Donnell y Juan José Sebreli lo fueran en los años 80).

La influencia del marxismo es también notoria en muchos investigadores e investigadoras, sobre todo en el campo de la historiografia. A modo de ejemplo (y bastante al azar) se pueden mencionar libros como Los origenes perdidos de la guerrilla en la Argentina, de Gabriel Rot (2000); Isurgencia obrera en la Argentina (1969-1976), de Ruth Werner y Facundo Aguirre (2006); La guerrilla fabril, de Hector Löbbe (2007); Zanon: una experiencia de lucha obrera, de Fernando Aiziczon (2009), y del mismo autor: Cultura politica, militantes y movilización (2017); Un 
Comahue violento, de Pablo Scatizza (2016); Los origenes de la clase obrera argentina, de Lucas Poy (2014); Sindicalismo revolucionario y movimiento obrero en la Argentina: de la gestación en el Partido Socialista a la conquista de la FORA (1900-1915), de Alejandro Belkin (2018).

No menos innegable resulta la impronta marxista (en mayor o menor medida) en los libros, artículos, reseñas, compilaciones, intervenciones y polémicas de Aldo Casas, Luis Mattini, Mabel Thwaites Rey, Pablo Bonavena, Flabián Nievas, Jorge Sanmartino, Gonzalo Pérez Álvarez, Daniel Desantis, Rubén Dri, Ricardo Azcuy Ameghino, Pablo Ghigliani, Guido Galafassi, Gabriela Scodeller, Federico Mare, José Luis Bonifacio, Agustín Santella, Martín Mosquera, Laura Fernández Cordero, Jorgelina Matusevicius, Miguel Candioti, Mariano Pacheco, Federico Manzone, Esteban Vedia, Ernesto Manzanares, Miguel Vedda, Daniel Campione, Adrián Piva, Juan Grijera, Guillermo Cieza, Mariano Feliz, Marina Kabat, Vera Carnovale, Agustín Nieto, Pablo Alabarces, Ariel Eidelman, Debora D'Antonio, Andrea D'Atri, Gustavo Contreras, Martín Beigel, Julián Verardi, Paula Varela, Hernán Díaz, Rodolfo Elbert, Clara Marticorena, Bruno Fornillo, Octavio Colombo, Julián Gallego, Laura Da Gracca, Corina Luchía, Andrea Barriga, Josefina Martínez, Ariane Díaz, Esteban Mercatante, Matías Maiello, Cristian Castillo, Raúl Cerdeiras, Alberto Bonnet, Cesar Altamira, Marcelo Starcenbaum, Natalia Romé, Pedro Karczmarczyk, Luis Garcia, Mariano Zarowsky y una lista virtualmente interminable. Y por supuesto, la producción escrita, aunque no sea su actividad fundamental, es siempre una caracteristica propia de los dirigentes marxistas partidarios: como Jorge Altamira o Emilio Albamonte (así como varios de los incluidos en el listado anterior).

$* * *$

Ingresando en la tercera década del siglo XXI, la cultura marxista en Argentina se muestra ciertamente vital: su productividad, en términos cuantitativos, no ha hecho más que crecer en los últimos años. Pero la productividad cuantitativa no es necesariamente un indicio confiable de vitalidad. No es lo mismo abundancia que calidad, ni presencia se identifica con influencia. ¿Cómo se presenta el estado de la cultura marxista desde perspectivas más cualitativas?

Comencemos por lo obvio: tanto el marxismo como el socialismo son fuerzas minoritarias en Argentina, en términos intelectuales y en términos políticos. Pero, quizá, ya no sean estrictamente marginales. Este crecimiento ha ido de la mano de algunos desplazamientos. Si durante los años 80 y 90 del siglo XX el epicentro de la producción intelectual marxista habían sido revistas independientes tanto de los partidos políticos como del mundo académico, en las dos primeras décadas del nuevo 
siglo se produjo gradualmente un cambio no abrupto pero apreciable. Las revistas independientes perdieron peso: Praxis y El Cielo por Asalto, cuya riqueza y originalidad fueron notables, tuvieron sin embargo corta vida en los años 80 y 90 respectivamente. Doxa desapareció en 2000. Tras dos décadas en las calles, Cuadernos del Sur dejó de salir en 2005. El Rodaballo apareció por última vez en 2006. El mismo año dejó de salir Taller. La aparición de Dialéktica se hizo intermitente en los últimos años. En contraste, la producción académicamente afincada, ubicada en algún nicho más o menos especializado de investigación, cobró mayor envergadura: Politicas de la Memoria-publicación del Centro de Documentación e Investigación de la Cultura de Izquierdas (Cedinci), cuyo primer número data de 1998- se ha convertido por derecho propio en epicentro de la investigación de alto nivel académico de la historia de las izquierdas. Archivos de Historia del Movimiento Obrero y la Izquierda (en actividad desde 2012) se concentra en la historia obrera y, en menor medida, de las izquierdas. En su corta vida, Nuevo Topo (2005-2008) fue una experiencia en buena medida "híbrida": buscaba un cierto agrupamiento de carácter generacional e ideológico relativamente amplio ("sensibilidad de izquierdas" fue el término empleado), pero inscribiéndose ya en un formato acentuadamente académico. Debates Urgentes (2012-2015) tuvo también un cierto carácter híbrido, pero con una impronta universitaria más marcada que en publicaciones anteriores. La corta experiencia de Contra-tiempos (apenas dos números en 20132014) muestra las dificultades de emprendimientos no académicos. Resistiendo todavia, Herramienta continua imperturbable, aunque con ciertos atisbos de progresiva inscripción en lógicas más académicas. Lucha armada en la Argentina fue una curiosa experiencia especializada en el tema homónimo, escrita por investigadores e investigadoras mayormente profesionales y con las reglas del arte, pero difundida muy popularmente.

Antagónica comienza su andadura, con un perfil académico pero con motivaciones político-ideológicas. La reciente aparición de la versión latinoamericana de Jacobin, con su director -Martín Mosqueraresidiendo en Buenos Aires, es una experiencia demasiado reciente como para evaluarla (aunque por lo visto es una publicación más bien política). Tanto la rama local del Consejo Latinoamericano de Ciencias Sociales (CLACSO) -en el que hay una abundante mas no exclusiva presencia marxista- como, a otra escala, el Centro de Investigaciones en Ciencias Sociales (CICSO) o el Centro de Investigación como Critica Práctica (CICP) son esencialmente nichos académicos. La academización, de hecho, empalma con una tendencia mundial, y ha afectado a todas las generaciones. Si se observa una creciente inserción académica de las generaciones veteranas, así como un relativo abandono de las 
expectativas y proyectos politico-culturales no académicos; quienes se iniciaron en años recientes lo han hecho abrumadoramente bajo la forma de la tesis doctoral. Desde luego: hay excepciones e hibridaciones. Pero la academización es creciente en líneas generales. Paralelamente, la producción intelectual al interior de los partidos de izquierda ya no es desdeñable. Ni en términos cuantitativos ni en términos cualitativos. Razón y Revolución ha devenido finalmente un partido político. Intersecciones -disponible en la web desde 2013- se halla vinculada a Democracia Socialista. En torno al PTS, florecen proyectos intelectuales como el Instituto del Pensamiento Socialista o la revista Ideas de Izquierda. La izquierda diario es un medio influyente: tensionado por lógicas estrechamente partidarias y perspectivas más amplias, ha amplificado las voces de la izquierda a escalas desconocidas en el pasado reciente.

No hay criterios sencillos ni plenamente objetivos para evaluar la calidad de las producciones intelectuales, por supuesto. La adscripción académica no es ningún indicio confiable o seguro: que una obra cumpla con los requisitos académicos no la hace necesariamente ni original ni de calidad. Más aún, en los últimos años la producción académica acaso esté favoreciendo el conformismo intelectual: corrección y erudición bastan y a veces sobran para hacer carrera académica; la originalidad (como la criticidad) es una consigna más invocada que practicada; las innovaciones audaces son una opción de alto riesgo. Con todo, podemos valernos de algunos indicadores para evaluar la calidad de la producción intelectual: la clásica erudición; la actualización y el conocimiento de producciones recientes; el no ocultar datos o documentos que no encajen fácilmente con las interpretaciones defendidas; la capacidad para exponer correctamente las tesis y los argumentos que se desea criticar (evitando la "falacia del muñeco de paja"); la genuina originalidad. Con estos aspectos en mente, se puede decir que una parte de la producción académica de corte marxista en la Argentina es de gran calidad. Las recientes obras de Juan Dal Maso sobre Gramsci, o la extensa obra Estrategia socialista y arte militar de Matías Maiello y Emilio Albamonte son producciones de una categoría intelectual con escasos o nulos precedentes en las producciones partidarias en décadas pasadas. Lo mismo podría decirse de la labor periodística de Fernando Rosso.

$$
* * *
$$

En 2008 Omar Acha postuló la posibilidad de que emergiera una Nueva Generación intelectual, caracterizada por su carácter colectivo, cooperativo, socialista, plebeyo, renovador e independiente. En consonancia con Acha, Miguel Mazzeo apostó -en Conjurar a Babel (2012)por la aparición de una nueva generación intelectual estrechamente 
vinculada a lo que llamó la "nueva nueva izquierda" o "la izquierda por venir". Sin embargo, la división de la más importante de las fuerzas de la llamada izquierda popular o independiente (el Frente Popular Darío Santillán), la orbitación de parte de este sector político hacia el kirchnerismo y la consolidación del Frente de Izquierda y de los Trabajadores (FIT), poco espacio dejó para proyectos de este tipo. La academización $y$, en menor medida, el desarrollo de espacios intelectuales vitales vinculados a organizaciones partidarias, sumados al atractivo del kirchnerismo en amplios círculos intelectuales, ha hecho que la emergencia de una Nueva Generación intelectual haya sido más un deseo que una realidad. Antes que la emergencia de una nueva generación con características propias nítidamente definidas, lo que se puede observar en general es una intelectualidad crecientemente académica, cada vez más especializada, con pocas inquietudes totalizantes, políticamente no muy activa y hegemonizada por perspectivas tibiamente progresistas. Más acotadamente, lo que se observa es una cultura marxista en crecimiento pero aún pequeña, diversa y variopinta, en general dispersa, en pugna o diálogo con otras tradiciones críticas (feminismos de diversa índole, perspectivas posmodernas, la llamada "opción descolonial", etc.) aunque con pocos debates intelectuales dignos de mención. Más recientemente, Santiago Roggerone -en Venir después, publicado en 2020- ha desarrollado reflexiones en clave generacional referidas a su propia generación en términos cronológicos: pero la emergencia de una "nueva generación" con nítidos contornos propios en términos cualitativos y claramente demarcada de las anteriores todavía no se constata.

Los temas abordados al interior de esta cultura marxista son claramente diversos. Incluyen una gran cantidad de estudios de movimientos sociales, conflictos laborales, historia de los trabajadores, de las mujeres, de las organizaciones y de la cultura de izquierdas; historia antigua y medieval; historia latinoamericana; investigaciones de intelectuales marxistas del pasado y del presente; reflexiones políticas y de coyuntura de diversa indole; propuestas programáticas y estratégicas; análisis filosóficos; estudios de economía y teoría económica; indagaciones en teoría o filosofía de la historia; estudios sociológicos de diverso tipo; ensayos de crítica cultural, etc. Los escritos centrados en Gramsci, la escuela de Frankfurt, Walter Benjamin o Louis Althusser han sido abundantes, en consonancia con tendencias globales. Ha habido alguna influencia también del marxismo analítico (aunque menor de la que hubiera sido deseable para desarrollar conocimiento científicamente riguroso). Se han producido estudios económicos marxistas desde diferentes perspectivas. La dimensión estética no ha estado ausente, como queda de manifiesto en las novelas de Martín Kohan o Andrés Rivera, no menos que en los ensayos de Damián Tabarovsky, Federico 
Mare o Mariana Dimópulos. El éxito de público del evento Marx Nace, en 2018, mostró un renovado interés por las ideas y la figura de Marx. $\mathrm{Su}$ influencia, tanto desde formas muy tradicionales como desde modulaciones esencialmente nuevas es innegable. Ingresando a la tercera década del nuevo siglo, el escenario que se nos presenta es el de una cultura marxista amplia y variopinta, una recepción sumamente diversa de la obra de Marx y sus continuadores. Antes que desaparición de ciertos tipos de marxismo (considerados muchas veces vetustos y obsoletos, aunque con criterios rara vez explicitados), lo que podemos observar en el contexto contemporáneo es un panorama mucho más diverso. Hay marxismos en claves ortodoxas tradicionales, para los que parece que el tiempo no pasara: organizaciones y autores que escriben en 2020 casi lo mismo y con el mismo lenguaje que podian haber escrito en 1980 o 1990. No hay, obviamente, nada intrínsecamente condenable en el hecho de mantener lealtad a ciertas teorías y/o lenguajes poco populares en un momento determinado. Pero sostener teorías sin sólidas respuestas a las críticas más actuales y sin ponerlas en discusión con los nuevos desarrollos es problemático; y no tener capacidad para renovar el lenguaje puede influir negativamente en la influencia politica. Pero no todo ha sido conservadurismo. Ha habido renovaciones interesantes desde coordenadas que son tanto una reafirmación como una innovación. Hay muchos nuevos problemas y temáticas analizados desde perspectivas socialistas. Hay búsquedas que tratan de establecer innovaciones mucho más radicales, constituir una nueva izquierda en ruptura más franca con el pasado (lo que en ocasiones ha desembocado en un abandono de la adscripción o la identidad marxista, hacia otros horizontes: como el feminismo o la opción descolonial). Hay hibridaciones de diferente tipo: marxismo y anarquismo (o autonomismo), marxismo y feminismo, marxismo y ecologismo, marxismo y posmodernismo, marxismo y psicoanálisis, Marx y Foucault, Lenin y Deleuze, Trotsky y Althusser, Benjamin y Gramsci, Adorno y Trotsky, Mariátegui y Marx. La calidad de estas producciones es tan desigual como sus perspectivas teóricas o posicionamientos políticos.

Por irónica combinación de causas y azares, en un país tan ubicuamente centrado en Buenos Aires, curiosamente, el desarrollo del marxismo tuvo en el pasado núcleos geográficamente periféricos. Germán Avé Lallemant fue el primer escritor marxista del país, en el siglo XIX, y lo hizo desde la remota San Luis. En los años 60 Córdoba fue el epicentro de la más rica e influyente experiencia intelectual marxista: Pasado y Presente. Empero, la otrora vanguardista Córdoba ha pasado a la retaguardia. Rosario mantiene pequeños núcleos marxistas. El Alto Valle de Río Negro y Neuquén ha sido una zona particularmente 
productiva en las últimas décadas. En la actualidad, sin embargo, la producción intelectual marxista o influida por el marxismo se concentra mayormente en Buenos Aires.

$$
* * *
$$

$\mathrm{Al}$ ingresar en la última década del siglo XX el futuro del marxismo como tradición intelectual y política se presentaba sombrío. No se podía descartar la desaparición lisa y llana. Treinta años después el escenario es claramente diferente. Lejos de haber desaparecido, la tradición marxista, como fuerza intelectual y como fuerza política, no sólo ha sobrevivido sino que parece haber conseguido, en Argentina, un cierto arraigo minoritario pero no despreciable. Este arraigo no está exento de ironías y paradojas. Como fuerza política su núcleo es indudablemente trotskista: el FIT-Unidad es abrumadoramente la fuerza mayoritaria entre las izquierdas anticapitalistas, lo cual no sólo es algo bastante inusual (en comparación con lo que sucede en otros sitios), sino que además implica la consolidación de fuerzas que podrían ser consideradas de la "vieja izquierda". En algunas de sus manifestaciones esta "vieja izquierda" trotskista está dando muestras de apertura y renovación. En paralelo, la mayor parte de los intentos que se propusieron ser más innovadores y romper más radicalmente con lo que consideraban "lacras de la vieja izquierda" (burocratismo, divisionismo, vanguardismo, sectarismo) han tendido a sucumbir a sus propias tensiones, ya sea por no haber podido superar algunos de los problemas que habian detectado con lucidez (por ejemplo la división), ya sea por ser absorbidos o esterilizados por fuerzas en modo alguno antisistémicas (como el kirchnerismo), ya sea por no haber podido hallar un espacio viable entre el kirchnerismo y la izquierda trotskista. Si esta es meramente la "fotografia" de un breve y pasajero momento o, por el contrario, una situación que perdurará en el tiempo, es pronto para juzgarlo.

Rica y vital, la cultura marxista en Argentina puede, sin embargo, dejar insatisfecha a la mayoría de sus implicados e implicadas: demasiado "trosca" para quienes desearian otros horizontes; excesivamente académica para quienes quisieran un marxismo más clásicamente "político"; todavía demasiado marxista para quienes anhelan una hibridación más ecléctica; apegada a imaginarios revolucionarios para quienes consideran que ya no hay ninguna revolución posible; muy pequeña para quienes sueñan con movimientos de masas; demasiado sectaria y radical para algunos, excesivamente acomodada para otros. El interrogante sobre si esta cultura podría cobijar o confluir en el futuro cercano con un proyecto reconociblemente anticapitalista no tiene, de momento, respuestas claras. Un optimismo desmedido estaría completamente fuera 
de lugar, al igual que cualquier tipo de nostalgia por pasados cercanos o lejanos. De momento, esto es lo que hay.

\section{Referencias}

Elster , J. (1987). Nuevas reflexiones sobre marxismo, funcionalismo y teoría de juegos. Zona Abierta, 43-44.

Sacristán, M. (1980). Anotación de lectura sobre Agnes Haller. En S. López Arnal (ed.). M.A.R.X (Máximas, aforismos y reflexiones con algunas variables libres). E1 Viejo Topo. 